\title{
Revision joint replacement surgeries of the hip and knee across geographic region and socioeconomic status in the western region of Victoria: a cross-sectional multilevel analysis of registry data
}

Sharon L. Brennan-Olsen ${ }^{1,2^{*}}$ (D, Sara Vogrin ${ }^{1,2}$, Stephen Graves ${ }^{3}$, Kara L. Holloway-Kew ${ }^{4}$, Richard S. Page ${ }^{4,5}$, M. Amber Sajjad ${ }^{4}$, Mark A. Kotowicz ${ }^{2,4,5}$, Patricia M. Livingston ${ }^{4}$, Mustafa Khasraw ${ }^{4,7}$, Sharon Hakkennes ${ }^{6}$, Trisha L. Dunning ${ }^{4}$, Susan Brumby ${ }^{4,8}$, Alasdair G. Sutherland ${ }^{4,9}$, Jason Talevski ${ }^{1,2}$, Darci Green ${ }^{1,2}$, Thu-Lan Kelly ${ }^{10}$, Lana J. Williams ${ }^{4}$ and Julie A. Pasco ${ }^{1,4,11}$

\begin{abstract}
Background: Residents of rural and regional areas, compared to those in urban regions, are more likely to experience geographical difficulties in accessing healthcare, particularly specialist services. We investigated associations between region of residence, socioeconomic status (SES) and utilisation of all-cause revision hip replacement or revision knee replacement surgeries.
\end{abstract}

Methods: Conducted in western Victoria, Australia, as part of the Ageing, Chronic Disease and Injury study, data from the Australian Orthopaedic Association National Joint Replacement Registry (2011-2013) for adults who underwent a revision hip replacement ( $n=542 ; 54 \%$ female) or revision knee replacement ( $n=353 ; 54 \%$ female) were extracted. We cross-matched residential addresses with 2011 census data from the Australian Bureau of Statistics (ABS), and using an ABS-derived composite index, classified region of residence according to local government areas (LGAs), and area-level SES into quintiles. For analyses, the control population ( $n=591,265 ; 51 \%$ female) was ABS-determined and excluded adults already identified as cases. Mixed-effects logistic regression was performed.

Results: We observed that $77 \%$ of revision hip surgeries and $83 \%$ of revision knee surgeries were performed for residents in the three most socially disadvantaged quintiles. In adjusted multilevel models, total variances contributed by the variance in LGAs for revisions of the hip or knee joint were only 1\% (SD random effects \pm 0.01 ) and 3\% (SD \pm 0.02 ), respectively. No differences across SES or sex were observed.

Conclusions: No differences in utilisation were identified between SES groups in the provision of revision surgeries of the hip or knee, independent of small between-LGA differences.

Keywords: Epidemiology, Geographic region, Revision joint replacements, Registry data, Social disadvantage

\footnotetext{
* Correspondence: sbrennan@unimelb.edu.au

'Department of Medicine, The University of Melbourne-Western Health, Level

3, WHCRE Building, Sunshine Hospital, 176 Furlong Road, St Albans,

Melbourne, VIC 3021, Australia

${ }^{2}$ Australian Institute for Musculoskeletal Science (AIMSS), The University of

Melbourne and Western Health, 176 Furlong Road, St Albans, Melbourne, VIC

3021, Australia

Full list of author information is available at the end of the article
}

(c) The Author(s). 2019 Open Access This article is distributed under the terms of the Creative Commons Attribution 4.0 International License (http://creativecommons.org/licenses/by/4.0/), which permits unrestricted use, distribution, and reproduction in any medium, provided you give appropriate credit to the original author(s) and the source, provide a link to the Creative Commons license, and indicate if changes were made. The Creative Commons Public Domain Dedication waiver (http://creativecommons.org/publicdomain/zero/1.0/) applies to the data made available in this article, unless otherwise stated. 


\section{Mini abstract}

Residents of rural/regional areas experience more difficulty accessing specialist healthcare providers compared to urban residents. Socially advantaged groups had the greatest uptake of arthroplasty, independent of small between-area differences. Despite few differences in revision surgery uptake across social groups, we caution against assumptions of no differences in need.

\section{Background}

The risk for joint diseases, such as arthritis, is greater in rural and farming communities when compared to the general population, due to occupational exposures related primarily to the agricultural industry [1-3]. Rural and regional residents experience out-of-pocket costs when seeking healthcare, and the inequities in specialist health care are enhanced by the effects of these costs [3, 4]. As we have previously suggested, and compared to urban residents, the uptake of elective surgery such as joint revision for rural/regional populations may be lower than the expected need for the revision surgery [1-3], an association often suggested as being related to geographical distance between patient and health service provider $[3,5,6]$.

A recent study by McGrory et al. examined current hip and knee revision surgery burden across Australia [7]. Until recently, the pattern of primary total joint replacement and relationships with age, sex, geographic location and socioeconomic status (SES) had not been described for the region of western Victoria [8]. One of the most important outcome measures of joint replacement surgery is revision rate [9]. We aimed to describe the pattern of revision surgeries as part of the Ageing, Chronic Disease and Injury (ACDI) study, which was launched to contribute locally-generated knowledge regarding chronic disease in this region [10].

\section{Methods}

\section{Australian Orthopaedic Association national joint replacement registry}

The Australian Orthopaedic Association National Joint Replacement Registry (AOANJRR) was established to monitor joint replacements from all public and private hospitals Australia-wide [11], and is the most complete and extensive set of joint replacement data in Australia [11]. As previously reported, AOANJRR data are crossreferenced with government hospital separation data as a verification process [12].

In our current analyses, we investigated revision joint replacement surgeries (performed for any diagnosis), whereby a revision joint replacement surgery was defined as "...re-operations of previous [joint] replacements where one or more of the prosthetic components are replaced, removed, or one or more components are added" [13], inclusive of all types of implants. We extracted data pertaining to the 941 revision joint replacement surgeries that had been performed during 20112013 , which encompassed knee or hip $(n=895)$; shoulder $(n=28)$; and elbow, ankle or wrist $(n=18)$. Due to cell counts, we examined only revision joint replacements of the knee and hip.

\section{Study population: cases, controls, and socioeconomic position}

Cases were defined as adults residing in western Victoria who had undergone a revision joint replacement of the knee $(n=4179 ; 56 \%$ female) and/or hip ( $n=3120 ; 54 \%$ female). We matched each patient's residential address to the Australian Bureau of Statistics (ABS) 2011 census data and, using the ABS-derived Index of Relative Socioeconomic Advantage and Disadvantage (IRSAD), defined area-level SES into quintiles based on cut-points for the Victorian population.

From the ABS cross-matching process, and using ABS concordance files, we identified the Local Government Area (LGA) within which cases and controls resided: of which the control population was 591,265 (51\% female). As previously published, we assumed that population figures remained similar between 2011 and 2013 [8].

\section{Statistical analyses}

We used similar multilevel modelling procedures (mixed effects logistic regression) employed in our previous studies [8] to now investigate the effect of various social factors on the revision of a knee or hip joint replacement. Analyses were performed using Stata 13.0 (StataCorp, Release 13, LP, College Station, Texas, USA).

\section{Results}

Table 1 presents descriptive characteristics of patients registered with the AOANJRR (2011-13) as having undergone a revision joint replacement surgery of the hip $(n=542)$ or knee $(n=353)$. We report that the greatest proportions of revision joint replacements of the hip and knee, respectively, were observed in women (53.7 and $54.1 \%$ ), those aged $60-69$ years (31.5 and $36.8 \%$ ) and $70-79$ years (32.5 and $30.3 \%$ ), and in the three most socially disadvantaged quintiles. The three most common reasons for revision of the hip joint were loosening/lysis (39.7\%), metal related pathology (15.1\%), and infection (13.6\%). For revision of the knee joint, the three most common reasons were loosening/lysis (37.1\%), infection (21.8\%), and pain (11.6\%).

Results from the multilevel modelling are presented in Table 2. The likelihood of revisions of the hip or knee differed minimally across the LGAs; differences were $2 \%$ (SD of random effects \pm 0.01 ) and $5 \%$ (SD \pm 0.03 ), respectively. In fully adjusted multilevel models, these 
Table 1 Characteristics of residents from Western Victoria who underwent a hip or knee revision surgery, 2011-13

\begin{tabular}{|c|c|c|c|}
\hline & \multicolumn{3}{|c|}{ Revision joint replacement surgeries } \\
\hline & Total $(n=895)$ & $\operatorname{Hip}(n=542)$ & Knee $(n=353)$ \\
\hline Women, n (\%) & $482(53.8 \%)$ & $291(53.7 \%)$ & $191(54.1 \%)$ \\
\hline \multicolumn{4}{|l|}{ Age group (years), n (\%) } \\
\hline $0-49$ & $37(4.1 \%)$ & $21(3.9 \%)$ & $16(4.5 \%)$ \\
\hline $50-59$ & $115(12.8 \%)$ & $66(12.2 \%)$ & $49(13.9 \%)$ \\
\hline $60-69$ & $301(33.6 \%)$ & $171(31.5 \%)$ & $130(36.8 \%)$ \\
\hline $70-79$ & $283(31.6 \%)$ & $176(32.5 \%)$ & $107(30.3 \%)$ \\
\hline$\geq 80$ & $159(17.8 \%)$ & $108(19.9 \%)$ & $51(14.4 \%)$ \\
\hline \multicolumn{4}{|l|}{ Socioeconomic quintiles, n (\%) } \\
\hline Quintile $1^{\mathrm{b}}$ & $236(26.4 \%)$ & $140(25.8 \%)$ & $96(27.2 \%)$ \\
\hline Quintile 2 & $258(28.8 \%)$ & $139(25.6 \%)$ & $119(33.7 \%)$ \\
\hline Quintile 3 & $219(24.5 \%)$ & $140(25.8 \%)$ & $79(22.4 \%)$ \\
\hline Quintile 4 & $148(16.5 \%)$ & $99(18.3 \%)$ & $49(13.9 \%)$ \\
\hline Quintile $5^{c}$ & $34(3.8 \%)$ & $24(4.4 \%)$ & $10(2.8 \%)$ \\
\hline \multicolumn{4}{|c|}{${ }^{\mathrm{a}}$ Reasons for joint replacement, n (\%) } \\
\hline Arthrofibrosis & $10(1.1 \%)$ & - & $10(2.8 \%)$ \\
\hline Erosion $^{d}$ & $11(1.2 \%)$ & $5(0.9 \%)$ & $6(1.7 \%)$ \\
\hline Fracture & 49 (5.5\%) & $46(8.5 \%)$ & $3(0.8 \%)$ \\
\hline Implant breakage e & $20(0.6 \%)$ & $13(2.4 \%)$ & $7(2.0 \%)$ \\
\hline Infection & $151(16.9 \%)$ & $74(13.6 \%)$ & $77(21.8 \%)$ \\
\hline Instability & $20(2.2 \%)$ & $1(0.2 \%)$ & $19(5.4 \%)$ \\
\hline Loosening/lysis & $346(38.7 \%)$ & 215 (39.7\%) & $131(37.1 \%)$ \\
\hline Metal-related pathology & $95(10.6 \%)$ & $82(15.1 \%)$ & $13(3.7 \%)$ \\
\hline Other $^{f}$ & $37(4.1 \%)$ & $24(4.4 \%)$ & $13(3.7 \%)$ \\
\hline Pain & $54(6.0 \%)$ & $13(2.4 \%)$ & $41(11.6 \%)$ \\
\hline Progression of disease & $21(2.3 \%)$ & - & $21(5.9 \%)$ \\
\hline Prosthesis dislocation & $65(7.3 \%)$ & $63(11.6 \%)$ & $2(0.6 \%)$ \\
\hline Wear ${ }^{9}$ & $16(1.8 \%)$ & $6(1.1 \%)$ & $10(2.8 \%)$ \\
\hline
\end{tabular}

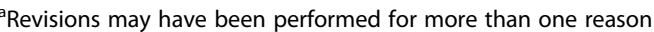

${ }^{\mathrm{b}}$ Most disadvantaged; ${ }^{\mathrm{C}}$ Most advantaged; ${ }^{\mathrm{d}}$ erosion includes chrondrolyses, acetabular, patella erosion; ${ }^{\mathrm{e}}$ implant breakage of the acetabular, femoral, head, patella, tibial, tibial insert, stem; ${ }^{f}$ other includes bearing dislocation, heterotopic bone, leg length discrepancy, malalignment, malposition, osteonecrosis, synovitis, tumour; ${ }^{g}$ 'wear' of the acetabular insert, patella, tibial, tibial insert

differences were reduced, whereby the total variance in revisions of the hip or knee contributed by the variance of LGAs was $1.0 \%$ (SD of random effects \pm 0.01 ), and $3.0 \%$ ( $\mathrm{SD} \pm 0.02$ ), respectively. In fully adjusted multilevel models, no sex differences were observed for revisions of the hip or knee.

\section{Discussion}

In the ACDI study region of western Victoria, Australia, we observed the greatest proportions of revision joint replacements of the hip and knee, respectively, in women, and in those aged 60 years or older. Approximately $80 \%$ of revision surgeries at the hip and knee were utilised by residents in the three most socially disadvantaged quintiles. However, after adjustments, multilevel modelling showed that total variances in revisions of the hip or knee joint contributed by the variance in LGAs were minor, and no differences between SES groups were observed.

The lack of differences in revision surgeries between SES groups contrasts with the expected higher rates of need for revisions in socially disadvantaged populations. We may speculate as to the lack of differences in the uptake of revision joint replacements across SES. It is possible that, as we have previously suggested for primary joint replacements [8], socially disadvantaged individuals may delay the utilisation of revision surgeries for a longer period than socially advantaged individuals. Delayed utilisation of elective surgeries by disadvantaged individuals may be related to a limited capacity to cover out-of- 
Table 2 Multilevel logistic regression models showing effects of sex, age and socioeconomic status on revision surgery

\begin{tabular}{|c|c|c|c|c|}
\hline & $\begin{array}{l}\text { Hip revisions } \\
\text { Odds ratios }(95 \% \mathrm{Cl})\end{array}$ & $p$ value & $\begin{array}{l}\text { Knee revisions } \\
\text { Odds ratios }(95 \% \mathrm{Cl})\end{array}$ & $p$ value \\
\hline Women & $1.01(0.85-1.19)$ & 0.94 & $1.04(0.84-1.29)$ & 0.69 \\
\hline Men (referent) & 1.00 & - & 1.00 & - \\
\hline \multicolumn{5}{|l|}{ Age group (years) } \\
\hline 0-39 & $0.01(0.003-0.02)$ & $\leq 0.001$ & $0.01(0.004-0.02)$ & $\leq 0.001$ \\
\hline $40-49$ & $0.08(0.04-0.13)$ & $\leq 0.001$ & $0.07(0.04-0.13)$ & $\leq 0.001$ \\
\hline $50-59$ & $0.32(0.24-0.42)$ & $\leq 0.001$ & $0.31(0.23-0.44)$ & $\leq 0.001$ \\
\hline 60-69 (referent) & 1.00 & - & 1.00 & - \\
\hline 70-79 & $1.68(1.36-2.07)$ & $\leq 0.001$ & $1.32(1.02-1.71)$ & 0.03 \\
\hline$\geq 80$ & $1.49(1.17-1.90)$ & 0.001 & $0.89(0.64-1.23)$ & 0.47 \\
\hline \multicolumn{5}{|l|}{ Socioeconomic status } \\
\hline Quintile $1^{\mathrm{a}}$ & $0.85(0.67-1.09)$ & 0.20 & $1.11(0.81-1.51)$ & 0.52 \\
\hline Quintile 2 & $0.87(0.68-1.10)$ & 0.25 & $1.37(1.02-1.83)$ & 0.03 \\
\hline Quintile 3 (referent) & 1.00 & - & 1.00 & - \\
\hline Quintile 4 & $1.11(0.85-1.44)$ & 0.44 & $0.98(0.68-1.40)$ & 0.92 \\
\hline Quintile $5^{b}$ & $0.86(0.56-1.34)$ & 0.51 & $0.65(0.34-1.27)$ & 0.21 \\
\hline Random effects of $L G A s^{c}$ & $0.20(0.11-0.36)$ & & $0.33(0.17-0.63)$ & \\
\hline$\%$ total variance contributed by LGAs ${ }^{d}$ & $1 \%$ & & $3 \%$ & \\
\hline$p$ value $e^{e}$ & & $\leq 0.001$ & & $\leq 0.001$ \\
\hline
\end{tabular}

${ }^{a}$ Most disadvantaged quintile of socioeconomic status; ${ }^{b}$ Most advantaged quintile of socioeconomic status; ${ }^{\mathrm{c} S t a n d a r d}$ deviation of the random effects of local government areas (LGAs); ${ }^{d}$ Percentage of the total variance contributed by the variance of the LGAs; ${ }^{e} p$ value for a likelihood ratio test. Bold text indicates significance at $p$ value $\leq 0.05$

pocket costs, the lack of social support during recovery, or the inability to take leave from employment. It may also be possible that the joint replacements of socially disadvantaged individuals experience greater 'wear and tear' than socially advantaged individuals due to having more physically demanding occupations [14]. The lack of associations we observed may be explained by the opposing factors of advantaged individuals undergoing revision surgeries without postponement, and disadvantaged individuals experiencing greater 'wear and tear' and thus having increased need.

Differences in preventive lifestyle behaviours may also result in variation in the need for surgeries. For instance, a randomised trial of exercise therapy vs patient education in 109 patients with hip osteoarthritis showed that exercise therapy reduced the need for primary joint replacement by $44 \%$ [15]. While there are no data investigating the role of exercise therapy on the need for revision joint replacement, exercise has been shown as beneficial in reducing pain and improving function in those with osteoarthritis, and thus it may be plausible that exercise therapy may result in reduced need for revision surgeries. The association between social advantage and physical activity has been well-documented [16, 17], and, although general exercise per se is not targeted at improving joint health, nonetheless, when contrasted with possible increased need yet delayed provision of revision surgeries by disadvantaged individuals, this may provide another plausible explanation as to why we did not observe any differences between social groups.

We observed similar rates of revision joint replacement surgeries for men and women. It is wellestablished that the prevalence of end-stage knee and/or hip arthritis, a condition that generally requires joint replacement surgery, is higher among women than men. Studies have shown that women with arthritis of the hip or knee suffer worse symptoms and greater disability, but may be less likely to undergo joint replacement surgery [18]. Should this be the case with revision surgeries, this might contribute to the lack of between-sex differences observed in the ACDI region.

Our study contributes to the emerging evidence-base regarding the ACDI region in terms of musculoskeletal disease, particularly revision joint replacements. Moreover, the findings are founded on the comprehensive data from the AOANJRR. We note limitations with this study, which should be considered when interpreting our findings. First, we may have been limited in our sample size to identify differences between the SES groups. Our analyses included all-cause revisions of the knee and hip, which encompassed a relatively small geographic area. Due to small numbers $(n=28)$ we were unable to investigate joint revisions of the shoulder. Obesity is likely to be a confounder in revision joint 
replacements and may possibly explain the greater proportion of revision surgeries in patients in the lower three quartiles of SES; however, this information, and other potentially confounding variable data, are not collected as part of registry data. The denominator for these analyses was everyone in the BSD region, rather than those that had a primary joint replacement: data linkage between primary and revision joint replacement over only a 3 year period would yield small numbers and was beyond the scope of this current investigation that was focused on informing the larger ACDI study. SES may have an impact on time to revision, rather than revision overall. Our analyses of LGAs and SES makes assumptions regarding heterogeneity of those residing in those areas, and finally, we acknowledge that the uptake of revision surgeries does not equate to need for surgery, nor does it reflect disease state.

\section{Conclusions}

In conclusion, although small between-LGA differences in utilisation were observed, no differences were detected between SES groups in the provision of revision TKR and THR. We speculate as to reasons for a lack of differences in revision surgeries across social groups, but caution against assumptions that no difference in need or uptake exists.

\section{Abbreviations \\ ABS: Australian Bureau of Statistics; ACDI: Ageing, Chronic Disease and Injury (study); AOANJRR: Australian Orthopaedic Association National Joint Replacement Registry; AOR: Adjusted odds ratio; BSD: Barwon Statistical Division; IRSAD: Index of Relative Socioeconomic Advantage and Disadvantage; LGA: Local Government Area; OR: Odds ratio; SD: Standard deviation; SES: Socioeconomic status}

\section{Acknowledgements}

We would like to thank the AOANJRR team for providing permission to use, and access to, these data.

\section{Authors' contributions \\ SLB-O, JAP, RSP and KLH-K conceived the study. SLB-O, JAP, KLH-K and RSP organised data access, and T-LK and SG facilitated and completed data ac- cess. SLB-O, KLH-K, RSP, MAS, MAK, PML, MK, SH, TLD, SB, AGS, LJW and JAP were involved in designing the ACDI study. T-LK undertook the geocoding for this study. DG and JT coded and cleaned data. SLB-O, DG, and JT drafted the manuscript. SLB-O guided the analyses and SV completed the analyses. SLB-O, SV, SG, KLH-K, RSP, MAS, MAK, PML, MK, SH, TLD, SB, AGS, JT, DG, T-LK, LW, and JAP were involved in the study design and contributed to the in- terpretation of the background data. SLB-O, SV, SG, KLH-K, RSP, MAS, MAK, PML, MK, SH, TLD, SB, AGS, JT, DG, T-LK, LJW, and JAP provided critical ap- praisal of the manuscript for important intellectual content; and SLB-O, SV, SG, KLH-K, RSP, MAS, MAK, PML, MK, SH, TLD, SB, AGS, JT, DG, T-LK, LW, and JAP approved the final manuscript.}

\section{Funding}

This study was funded by the Western Alliance Academic Health Science Centre, a partnership for research collaboration between Deakin University, Federation University and 11 health service providers operating across western Victoria. The funding body had no role in study design, data collection, analyses, interpretation or in writing the publication. SLB-O and LW are each supported by a National Health and Medical Research Council (NHMRC, of Australia) Career Development Fellowship (1107510, and 1064272, respectively), and JT is supported by a NHMRC Public Health and
Health Service Postgraduate Research Scholarship (1151089). KLH-K is supported by an Alfred Deakin Postdoctoral Research Fellowship from Deakin University, and MAS is supported by a Deakin University stipend via the IMPACT Strategic Research Centre.

\section{Availability of data and materials}

The datasets generated and analysed during the current study are not publicly available due to the information collected by the AOANJRR being protected by quality assurance confidentiality (under the Health Insurance Act of 1973), which ensures that patients, surgeons, hospitals and government information supplied to the AOANJRR remains confidential and secure. The AOANJRR governs the dataset supporting the conclusions of this article (https://aoanjrr.sahmri.com/).

\section{Ethics approval and consent to participate}

The Australian Orthopaedic Association National Joint Replacement Registry (AOANJRR) Data Review Committee approved access to AOANJRR data for this study, and the Barwon Health Human Research Ethics Committee approved the Ageing, Chronic Disease and Injury (ACDI) study.

\section{Consent for publication}

Not applicable.

\section{Competing interests}

Sharon Brennan-Olsen, Sara Vogrin, Kara Holloway-Kew, Muhammad Sajjad, Mark Kotowicz, Patricia Livingston, Mustafa Khasraw, Sharon Hakkennes, Trisha Dunning, Susan Brumby, Alasdair Sutherland, Jason Talevski, Darci Green, Thu-Lan Kelly, Lana Williams, and Julie Pasco declare that they have no conflict of interest. Richard Page is a Committee member of the AOANJRR, and Steven Graves is the Director of the AOANJRR, from where data for these analyses were extracted.

\section{Author details}

'Department of Medicine, The University of Melbourne-Western Health, Level 3. WHCRE Building, Sunshine Hospital, 176 Furlong Road, St Albans, Melbourne, VIC 3021, Australia. ${ }^{2}$ Australian Institute for Musculoskeletal Science (AIMSS), The University of Melbourne and Western Health, 176 Furlong Road, St Albans, Melbourne, VIC 3021, Australia. ${ }^{3}$ Australian Orthopaedic Association National Joint Replacement Registry, SAHMRI, Level 4, North Terrace, Adelaide, SA 5000, Australia. ${ }^{4}$ Deakin University, Pigdon Road, Geelong, VIC 3220, Australia. ${ }^{5}$ Barwon Centre for Orthopaedic Research and Education (B-CORE), Barwon Health and St John of God Hospital, Myers Street, Geelong, VIC 3220, Australia. ${ }^{6}$ Barwon Health, University Hospital Geelong, Ryrie Street, Geelong, VIC 3220, Australia. ${ }^{7}$ University of Sydney, Parramatta Road, Camperdown, Sydney, NSW 2006, Australia. ${ }^{8}$ National Centre for Farmer Health, Western District Health Service, Tyers Street, Hamilton, VIC 3300, Australia. ${ }^{9}$ South West Healthcare, 25 Ryot Street, Warrnambool, VIC 3280, Australia. ${ }^{10}$ School of Pharmacy and Medical Sciences, University of South Australia, City East Campus, North Terrace, Adelaide, SA 5001, Australia. "'Department of Preventive Medicine and Epidemiology, Monash University, Alfred Centre, 99 Commercial Road, Prahran, VIC 3004, Australia.

Received: 24 October 2018 Accepted: 11 June 2019

Published online: 25 June 2019

\section{References}

1. Kirkhorn S, Greenlee RT, Reeser JC. The epidemiology of agriculture-related osteoarthritis and its impact on occupational disability. WMJ. 2003;102(7): 38-44.

2. Andersen S, Thygesen LC, Davidsen M, Helweg-Larsen K. Cumulative years in occupation and the risk of hip or knee osteoarthritis in men and women: a register-based follow-up study. Occup Environ Med. 2012;69(5):325-30.

3. Brennan-Olsen S, Vogrin S, Holloway KL, Page RS, Sajjad MA, Kotowicz MA, et al. Geographic region, socioeconomic position and the utilisation of primary total joint replacement for hip or knee osteoarthritis across western Victoria: a cross-sectional multilevel study of the Australian Orthopaedic Association National Joint Replacement Registry. Arch Osteoporos. 2017;(1):1.

4. NRHA. Income inequality experienced by the people of rural and remote Australia: submission to the senate inquiry into the extent of income inequality in Australia. Canberra; 2014. https://ruralhealth.org.au/sites/ 
default/files/documents/nrha-policy-document/submissions/sub-incomeinequality-inquiry-15-oct-2014.pdf.

5. Hartley D. Rural health disparities, population health, and rural culture. Am J Public Health. 2004:94(10):1675-8.

6. Australian Institute of Health and Welfare. Rural and remote health: indicators of health status and determinants of health. Canberra; 2008. Rural Health Series, Number 9; Category Number PHE 97. Published by AlHW.

7. McGrory BJ, Etkin CD, Lewallen DG. Comparing contemporary revision burden among hip and knee joint replacement registries. Arthroplasty Today. 2016;2(2):83-6.

8. Brennan-Olsen SL, Vogrin S, Holloway KL, Page RS, Sajjad MA, Kotowicz MA, Livingston PM, Khasraw M, Hakkennes S, Dunning TL, Brumby S, Pedler D, Sutherland A, Venkatesh S, Williams L, Duque G, Graves S, Lorimer M, Pasco JA. Geographic region, socioeconomic position and the utilisation of primary total joint replacement for hip and knee osteoarthritis across western Victoria: a cross-sectional multilevel study of the Australian Orthopaedic Association National Joint Replacement Registry. Arch Osteoporosis. 2017;12(1):97

9. Labek G, Thaler M, Janda W, Agreiter M, Stockl B. Revision rates after total joint replacement: cumulative results from worldwide joint register datasets. J Bone Joint Surg Br. 2011;93(3):293-7.

10. Sajjad MA, Holloway KL, Kotowicz MA, Livingston PM, Khasraw M, Hakkennes S, Dunning TL, Brumby S, Page RS, Pedler D, Sutherland A, Venkatesh S, Brennan-Olsen SL, Williams L, Pasco JA. Ageing, chronic disease and injury: a study in western Victoria (Australia). J Public Health Res. 2016:5(678):81-6.

11. Australian Orthopedic Association National Joint Replacement Registry. Demographics of hip and knee arthroplasty. Adelaide; 2009. https://aoanjrr. sahmri.com/documents/10180/42728/Annual+Report+2009.

12. Brennan SL, Stanford T, Wluka AE, Page RS, Graves SE, Kotowicz MA, et al. Utilisation of primary total knee joint replacements across socioeconomic status in the Barwon Statistical Division, Australia, 2006-2007: a crosssectional study. BMJ Open. 2012;2:e001310.

13. Australian Orthapedic Association National Joint Replacement Registry. Hip, knee \& shoulder arthroplasty: 2017 annual report. Adelaide: AOA; 2017.

14. Beenackers MA, Kamphuis CB, Giskes K, Brug J, Kunst AE, Burdorf A, van Lenthe FJ. Socioeconomic inequalities in occupational, leisure-time, and transport related physical activity among European adults: a systematic review. Int J Behav Nutr Phys Act. 2012;9(1):116.

15. Svege I, Nordsletten L, Fernandes L, Risberg MA. Exercise therapy may postpone total hip replacement surgery in patients with hip osteoarthritis: a long-term follow-up of a randomised trial. Ann Rheum Dis. 2013;74(1):164-9.

16. Gidlow $C$, Johnston $L H$, Crone D, Ellis N, James D. A systematic review of the relationship between socioeconomic position and physical activity. Health Educ J. 2006;65(4):338-67.

17. Stalsberg R, Pederson AV. Effects of socioeconomic status on the physical activity in adolescents: a systematic review of the evidence. Scand J Med Sci Sports. 2010;20(3):368-83.

18. Hawker GA, Wright JG, Coyte PC, Williams JI, Harvey B, Glazier R, Badley EM. Differences between men and women in the the rate of use of hip and knee arthroplasty. N Engl J Med. 2000;342(14):1016-22.

\section{Publisher's Note}

Springer Nature remains neutral with regard to jurisdictional claims in published maps and institutional affiliations.

Ready to submit your research? Choose BMC and benefit from:
- fast, convenient online submission
- thorough peer review by experienced researchers in your field
- rapid publication on acceptance
- support for research data, including large and complex data types
- gold Open Access which fosters wider collaboration and increased citations
- maximum visibility for your research: over 100M website views per year
At BMC, research is always in progress.
Learn more biomedcentral.com/submissions

